\title{
A Case of Dystocia Induced by Misuse of Oxytocin in a Boerboel Bitch
}

\author{
Khalid Talha Biobaku ${ }^{1}$, Lukman Oladimeji Rajii* , Ganiu Jimoh Akorede ${ }^{1}$, \\ Ismail Ayoade Odetokun ${ }^{3}$, Saliu Akanni Ameen ${ }^{4}$
}

${ }^{I}$ Department of Veterinary Pharmacology and Toxicology, University of Ilorin, Ilorin, Kwara State, Nigeria

${ }^{2}$ Department of Theriogenology and Production, University of Ilorin, Ilorin, Kwara State, Nigeria

${ }^{3}$ Department of Veterinary Public Health and Preventive Medicine, University of Ilorin, Ilorin, Kwara State, Nigeria ${ }^{4}$ Department of Veterinary Medicine, University of Ilorin, Ilorin, Kwara State, Nigeria

\begin{tabular}{l} 
A R T I C L E I N F O \\
\hline Article history: \\
Received 11 June 2016 \\
Accepted 14 August 2016 \\
Available online, ISSN: 2148-127X \\
Keywords: \\
Bitch \\
Dystocia \\
Dead fetus \\
Oxytocin \\
Veterinary doctors
\end{tabular}
A B S T R A C T

A two year old boerboel bitch with dark greenish vaginal discharge and history of over 24 hours of difficult labor was presented to the Veterinary Teaching Hospital University of Ibadan for clinical examination and treatment. The owner had wrongfully given oxytocin after observation of signs of parturition. Following careful physical and clinical examinations of the bitch by Veterinary doctors, dystocia due to obstruction of maternal birth canal by a dead fetus was diagnosed. Treatment regimen was by digital manipulation which stimulated cervical dilatation and careful delivery of dead fetus via the vagina. Thereafter, oxytocin was administered to augment the bitch's weak uterine contraction. Four weak puppies were delivered out of which three survived following adequate treatment.

${ }^{*}$ Corresponding Author:

E-mail: raji.lo@unilorin.edu.ng

\section{Introduction}

Dog breeding in Nigeria has become a very lucrative business and its practice cuts across all social cadres. Dogs are bred for social and economic reasons and gains. The foreign breeds of dogs like the Alsatian, Rottweiler and especially Boerboel are the most commonly bred as they are highly priced and the demand for their puppies is very high. A puppy of a Boerboel for instance, can sell for as much as one hundred and twenty thousand naira and a litter size of fifteen puppies (commonly experienced in this breed), can fetch a breeder a fortune (Oboebgulem and Nwakonobi 1989; Anosike et al, 2004). However, adequate management in terms of nutrition, housing and Veterinary care is essential for the survival of the stud, bitch and puppies (Newbury et al, 2010).

Unfortunately, for selfish reasons or "maximum profit mentality", dog breeders try as much as possible to evade Veterinary care cost by administering drugs and vaccines to their dogs themselves. Hence, abuse and misuse of drugs is commonly practiced often resulting in loss of lives of puppies, bitches and studs as well as time, energy and money. Veterinarians are usually consulted only on the last resort especially in difficult cases which at times are too late to intervene or rescue (Marian, 2007). This paper highlights a case of misuse of a reproductive hormone oxytocin erroneously administered by a dog breeder on a two year old Boerboel pregnant bitch and the successful intervention by Veterinarians to save the bitch and puppies.

\section{Case report}

\section{History}

A two year old boerboel bitch having dark greenish vaginal discharge and history of over 24 hours of labor was presented to the Veterinary Teaching Hospital University of Ibadan for examination and treatment. The owner who is a dog breeder said that he had previously administered oxytocin (of unknown dosage) to the bitch after observing signs of labor but without any delivery of any puppy.

\section{Clinical Examinations and Observations}

The body weight and rectal temperature were $34 \mathrm{~kg}$ and $39.3^{\circ} \mathrm{C}$ respectively. The bitch was slightly depressed with manifested "head dropping". It intermittently strained which was followed by a foul smelling dark greenish vaginal discharge. On abdominal palpation, there were evidences of fetuses in the uterus. A dead fetus with a transverse presentation was observed obstructing the bitch birth canal at the pelvic outlet following palpation via the vagina using the fore left finger with gloves on. Ultrasound scan using the B-mode real time ultrasound machine (Biocare Ultrasonic Diagnostic Equipment Model: BU-907) confirmed viable fetuses in the uterus of the boerboel bitch (Figure 1). 


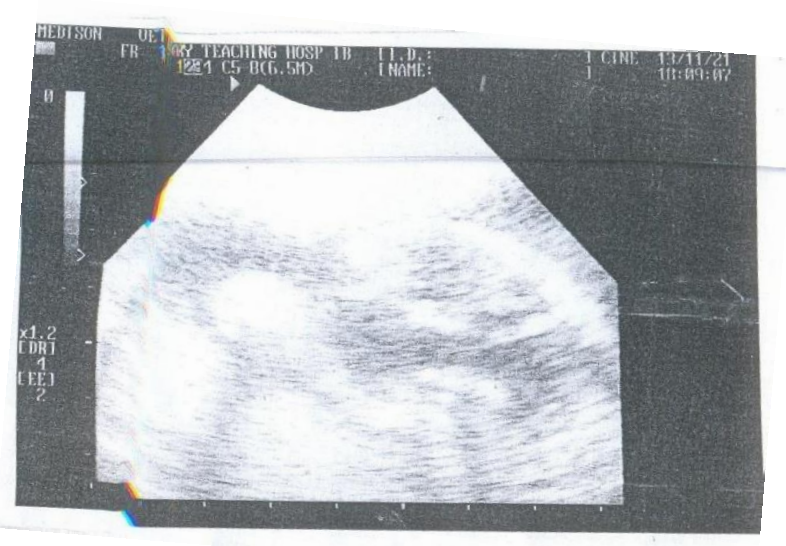

Figure 1 Ultrasonograph showing hypo echoic areas of amniotic fluid and hyper echoic areas of fetuses.

\section{Diagnosis}

Based on the history, physical, clinical examinations and observations, fetal dystocia due to obstruction of maternal birth canal at the pelvic outlet by a dead puppy was diagnosed.

\section{Treatment Regimen}

Manipulatory delivery: Firstly, the dead puppy obstructing the bitch birth canal was delivered by digital manipulation via the vagina. This induced cervical dilatation.

Therapeutic delivery: Thereafter, oxytocin 5 IU was administered intramuscularly and about 30 minutes later, the bitch delivered the first live puppy which was weak. Three other live but slightly weak puppies were also delivered at an average interval of one and half hour.

Post partum management: Dam-neonate relationship was established with adequate supportive neonatal care. Penicillin-streptomycin was administered intramuscularly to the bitch for five consecutive days.

\section{Result/Case outcome}

Following adequate treatment and care, the boerboel bitch survived along-side with three out of the four puppies that were delivered.

\section{Discussion}

In this case, fetal dystocia in a boerboel bitch was relieved by digital manipulation and use of exogenous oxytocin. The dystocia was induced by the initial erroneous use of oxytocin by the owner (a dog breeder) prior to the full establishment of the first stage of labor; which comprises of uterine contraction, Ferguson's reflex (fetal contact with the cervix), cervical dilatation and water break (Pretzer, 2008). Oxytocin was administered (ignorantly) by the owner (a non-professional) while the cervix was still closed because Ferguson's reflex was yet to be established. This led to a more vigorous uterine contraction forcing fetal expulsion while the cervix was still closed leading to the death of the first puppy with transverse presentation and subsequent obstruction of the maternal birth canal at the pelvic outlet. This was evident by the dark greenish vaginal discharge indicating fetal compromise when the bitch was presented about 24 hours later (Barber, 2003). The dead fetus was removed via the vagina after digital manipulation. This induced cervical dilatation paving the way for the second stage of labor (when actual delivery the fetuses occur). But because the bitch was weak and depressed, uterine contraction was poor and requires to be augmented for safe delivery of the puppies as well as survival of the bitch. Hence, oxytocin which is a reproductive hormone (that is released by the pituitary gland that causes increased uterine contraction and milk let down), was administered intramuscularly to the bitch (Wiebe, 2009). About thirty minutes thereafter, the bitch delivered the first live puppy which was weaker than the subsequent three puppies. The average interval between the delivery of each puppy was about one and half hour. The third stage of labor (i.e. placenta delivery) was also well established with minimal difficulty. Damneonate bonding was then established with subsequent adequate supportive neonatal care (Johnson et al., 2001; Linde-Fosberg and Persson, 2007). Penicillinstreptomycin was administered intramuscularly to the bitch for five consecutive days. The first puppy died two days later while the remaining three survived.

The canine industry is fast growing and is playing a significant role in the Nigerian economy and there is room for improvement and greater socio-economic gains. Dog breeding could be highly lucrative especially if well managed (Bell, 1999). However, quackery practices such as the one established in this case should be discouraged for this lofty height to be attained (Marian, 2007). All stakeholders should play their roles accordingly. Dog breeders who are not trained Veterinarians should not pertake in the treatment of dogs and handling of cases which are meant for the professionals. The professional intervention of the Veterinarians in this case corrected the grievous mistake made by the dog owner and saved the lives of both the boerboel bitch and three out of its four puppies which could have been a great financial loss as well as emotional trauma to the owner himself. The abuse and misuse of oxytocin by this individual who lacked knowledge about the pharmacological and reproductive effect this drug is just one of many quackery practices that is not just a threat to the survival of the canine industry but also to the Veterinary practice which play significant roles in the economy of not only Nigeria but the world at large. We recommend that penalties should be put in place and/or implemented in order to deter or totally abolish these quackery practices for the maximum benefits of all stakeholders.

\section{References}

Anosike JC, Nwoke EB, Ukaga CN, Madu NGJ, Dozie INS. 2004. Aspects of intestinal helminth parasites of dogs in World BankAssisted Housing Estate, new Owerri, Nigeria. Afric. J. of Appl. Zool. and Envir. Biol. 6: 25-29.

Barber JA. 2003. Parasites and dystocia In: Small animal Theriogenology. Margaret V Root Kustrittz, Butterworth Hienenann. An imprint of Elsevier Sci., USA pp 241-281. 
Bell JS. 1999. “ Developing Healthy Breeding Programs”, Canine Health Conference, AKC Canine Health Foundation, St. Louis MO.

Johnson SD, Kustritz MVR, Olson PNS. 2001. The neonate from birth to weaning. In: JohnsonSD (ed): Canine and feline Theriogenology INB Sanders, Philadephia pp 146-157.

Linde-Fosberg C, Persson G. 2007. Asurvey of dystocia in the Boxer breed. Acta

Veterinaria Scandina Vica 49: 8 http://www.actavetscand.com/ content/49/1/8. Retrived 8/11/15.

Marian CH. 2007. Quackery and Science in Veterinary Education. Based on the keynote address to the Akademie fur Tiergesundheit (AfT), Petersberg/Bonn.
Newbury S, Blinn MK, Bushby PA, Cox CB, Dinnage JD, Griffin B, Hurley KF, Isaza N, Jones W, Miller L, O'Quin J, Patronek GJ, Smith-Blackmore M, Spindel M. 2010. Guidelines for Standards of care in animal shelters.

Oboebgulem SI, Nwakonobi LE. 1989. Population density and ecology of dogs in Nigeria a pilot Study. Review Scientifique at Technique- officer. International Epizooties 8: 733-745.

Pretzer SD. 2008. Parturitions and dystocia. Medical management of canine and feline dystocia. Theriogenology 70: 332-336.

Wiebe VJ, Howard JP. 2009. Pharmacologic Advances in canine and feline reproduction. Topical Review. 